\title{
SENTIMENTOS DE MÃES ATRIBUIDOS À HOSPITALIZAÇÃO DE UM FILHO*
}

Sarah Vieira Figueiredo', Ilvana Lima Verde Gomes², Viviane Peixoto dos Santos Pennafort ${ }^{3}$, Ana Ruth Macêdo Monteiro ${ }^{4}$, Juliana Vieira Figueiredo ${ }^{5}$

\begin{abstract}
RESUMO: Objetivou-se descrever os sentimentos de mães ao vivenciarem o internamento dos filhos. Pesquisa descritiva, qualitativa, desenvolvida em 2012 em hospital de referência pediátrica de Fortaleza-Ceará, por meio de entrevista semiestruturada com mães acompanhantes após aprovação do Comitê de Ética. A partir da análise das entrevistas, foram delimitadas duas categorias: sentimentos gerados na mãe pelo adoecimento do filho e estratégias para enfrentar o sofrimento. Evidencia-se a necessidade de maior atenção e interação, por parte dos profissionais de saúde, com as mães acompanhantes, de forma a promover cuidado humanizado, envolvendo o binômio mãe e filho.

DESCRITORES: Criança hospitalizada; Mães; Humanização da assistência; Enfermagem.
\end{abstract}

\section{MOTHERS' FEELINGS ATTRIBUTED TO THE HOSPITALIZATION OF THEIR CHILD}

ABSTRACT: This study aimed to describe the feelings of mothers in experiencing the hospitalization of their child. This descriptive, qualitative research was undertaken in 2012 in a hospital, a center of excellence in Pediatrics, in FortalezaCeará, by means of a semi-structured interview held with mothers accompanying their children, following approval from the Ethics Committee. Based on the analysis of the interviews, two categories were delimited: feelings created in the mother by the falling-ill of her child and strategies for coping with the suffering. The need is evidenced for greater care and interaction on the part of the health professionals with the mothers accompanying children, so as to promote humanized care, involving the mother-child unit.

DESCRIPTORS: Hospitalized child; Mothers; Humanization of care; Nursing.

\section{SENTIMIENTOS DE MADRES ATRIBUIDOS A LA HOSPITALIZACIÓN DE UN HIJO}

RESUMEN: La finalidad del estudio fue describir los sentimientos de madres cuando pasaron por el internamiento de los hijos. Investigación descriptiva, cualitativa, desarrollada en 2012 en hospital de referencia pediátrica de Fortaleza, Ceará, por medio de entrevista semiestructurada con madres acompañantes después de aprobación de la Comisión de Ética. Con base en el análisis de las entrevistas, fueron delimitadas dos categorías: Sentimientos generados en la madre por la enfermedad del hijo y Estrategias para afrontar el sufrimiento. Se evidencia la necesidad de más atención e interacción por los profesionales de salud con las madres acompañantes, de forma a promover cuidado humanizado, involucrando el binomio madre e hijo. DESCRIPTORES: Niño hospitalizado; Madres; Humanización de la asistencia; Enfermería.

\footnotetext{
*Extraído da monografia “Adoecimento e hospitalização de um filho: significados do internamento segundo o olhar da mãe" apresentada ao Curso de Graduação em Enfermagem da Universidade Estadual do Ceará - UECE, em 2012.

${ }^{1}$ Enfermeira. Professora do Programa de Pós-Graduação em Enfermagem da UECE. Membro do Grupo de Pesquisa Cuidados à Saúde da Criança e do Adolescente.

${ }^{2}$ Enfermeira da Educação Permanente em Saúde e do Comitê de Ética em Pesquisa do Hospital Geral de Fortaleza. Doutora em Saúde Coletiva. Professora do Curso de Graduação em Enfermagem e dos Programas de Pós-Graduação em Saúde Publica e Mestrado Profissional Saúde da Criança e do Adolescente da UECE. Membro do Grupo de Pesquisa Cuidados à Saúde da Criança e do Adolescente. ${ }^{3}$ Enfermeira. Mestre em Cuidados Clínicos em Saúde. Doutoranda pelo Programa de Pós-Graduação em Cuidados Clínicos em Saúde e Enfermagem da UECE. Bolsista CAPES. Membro do Grupo de Pesquisa Cuidados à Saúde da Criança e do Adolescente e Enfermagem. ${ }^{4}$ Enfermeira. Psicodramista. Doutora em Enfermagem. Professora do Curso de Graduação em Enfermagem e do Programa de PósGraduação em Cuidados Clínicos em Saúde da UECE. Professora da Faculdade Metropolitana de Fortaleza. Membro do Grupo de Pesquisa em Enfermagem, Educação, Saúde e Sociedade.

${ }^{5}$ Enfermeira. Mestre em Enfermagem. Professora da Centro de Ensino Unificado de Teresina-Piauí.
}

Autor correspondente:

Recebido: 22/12/2012

Sarah Vieira Figueiredo Aprovado: 22/05/2013

Universidade Estadual do Ceará

Rua Pinheiro Maia, 150 - 60822-720 - Fortaleza-CE-Brasil

E-mail: sarahvfigueiredo@gmail.com

Cogitare Enferm. 2013 Jul/Set; 18(3):552-7 


\section{INTRODUÇÃO}

Até poucas décadas, mãe e filho viam-se afastados durante a hospitalização da criança, fato que gerava sofrimento tanto para a mãe, por não poder estar ao lado do filho, quanto para a criança, pois deixava o lar para vivenciar um ambiente novo, com pessoas estranhas e sem a presença de familiar durante a internação. Esta, por si só, constitui experiência estressante para a criança, devido às situações em que ocorre e por envolver profundas adaptações do paciente às várias mudanças durante esse período, em detrimento do tratamento e dos diversos procedimentos necessários para a sua reabilitação ${ }^{(1)}$.

A partir de 1990, no Brasil, com a consolidação do Estatuto da Criança e do Adolescente (ECA) a criança passou a ter o direito a acompanhante no ambiente hospitalar, durante todo o período de internação. Esse fato tem contribuído para a melhoria do tratamento da criança, promovendo assistência humanizada ${ }^{(2)}$.

A hospitalização infantil é considerada um evento estressante para toda a família, no entanto, é a figura materna a mais presente durante a internação, fato que pode ser compreendido a partir do momento em que entendemos a dimensão do apego existente entre mãe e filho ${ }^{(3)}$. A mãe, ao acompanhar o internamento do filho, sofre ao seu lado, pois o adoecimento e a internação são fontes de ansiedade que, muitas vezes, são intensificadas pela falta de diagnóstico estabelecido ou por dúvidas não esclarecidas sobre o estado de saúde e processo terapêutico ${ }^{(4)}$.

Nesse contexto, a hospitalização do filho constitui experiência difícil e triste que provoca dor e desespero. A dor está relacionada ao fato de ter um filho doente e hospitalizado, que a impede de desenvolver suas atividades rotineiras ${ }^{(5)}$. O sofrimento da mãe acompanhante pode ser agravado pela preocupação com os outros filhos que ficaram em casa, distanciamento do companheiro e trabalho, desgaste físico e emocional, entre outros aspectos particulares ${ }^{(6)}$.

Portanto, percebe-se que os profissionais de saúde não mais podem admitir a criança fora do contexto familiar, uma vez que a mãe faz parte da atenção à criança, sendo essa também objeto de cuidado. No processo de internação pediátrica é preciso valorizar o vínculo criança-mãe, bem como esclarecer, orientar e proporcionar segurança ao binômio, auxiliando a mãe diante de conflitos, medos e aumento de responsabilidades resultantes da internação ${ }^{(7)}$. Logo, existe a necessidade de que o enfermeiro desenvolva atividade assistencial que abranja não apenas o cuidado à criança hospitalizada, mas também seu universo social e familiar ${ }^{(8)}$.

A partir desse entendimento, objetivando aprofundamento na temática, realizou-se buscas nas bases de dados LILACS, MEDLINE e SciELO, utilizando-se os descritores "criança hospitalizada", "sentimentos" e "mãe", encontrando-se apenas dois artigos publicados nos últimos cinco anos, que abordam o sofrimento psíquico de mães ao acompanharem a hospitalização do filho. Um desses foi realizado em Unidade de Terapia Intensiva, que possui características diferentes da unidade de internação pediátrica ${ }^{(9-10)}$.

Destaca-se, portanto, a carência de pesquisas atuais que tragam ao debate as experiências e os sentimentos das mães ao acompanharem a hospitalização de seus filhos e que contribuam para a humanização do cuidado dos profissionais de saúde junto à família e criança ${ }^{(11)}$.

Diante do exposto, desenvolveu-se esta pesquisa com objetivo de descrever os sentimentos de mães de crianças hospitalizadas ao vivenciarem seu internamento. Com a chegada da mãe ao ambiente hospitalar, tornou-se indispensável a reestruturação desse ambiente, da visão dos profissionais acerca do papel da mãe e da forma de lidar com esta durante sua permanência no hospital. Os resultados desta pesquisa podem auxiliar em discussões sobre o assunto e possibilitar melhor compreensão, por parte dos profissionais, acerca dos aspectos subjetivos e pessoais inerentes as mães acompanhantes, o que poderá contribuir, consequentemente, para avanços na relação de cuidado entre profissionais de saúde, criança e família.

\section{MÉTODO}

Estudo de natureza descritiva, ancorando-se na abordagem qualitativa que se afirma no campo da subjetividade, com o universo de significados, crenças, valores, entre outros ${ }^{(12)}$. Foi desenvolvido em hospital público estadual, de nível terciário e direcionando, exclusivamente à atenção infantil e do adolescente, localizado em Fortaleza-Ceará, no período de agosto à setembro de 2012. Escolheu-se, de modo aletório, uma unidade para o desenvolvimento da pesquisa, a qual se denominou de $\mathrm{X}$ que recebia crianças e adolescentes nas especialidades de gastroenterologia e nefrologia, totalizando 25 leitos.

O estudo respeitou os princípios bioéticos postulados pela Resolução 196/96, do Conselho Nacional de Saúde ${ }^{(13)}$ e vigente à época do estudo, os quais se 
referem à autonomia, beneficência, não maleficência e justiça. O projeto foi aprovado pelo Comitê de Ética e Pesquisa do referido hospital, conforme parecer 031/2011.

Os critérios de inclusão para a participação da pesquisa foram: ser mãe, independente da idade e do número de filhos, estar com filho internado no setor do estudo há, no mínimo, uma semana e ser até a terceira internação da criança. Os critérios de exclusão foram: mãe apresentar alguma deficiência mental que prejudicasse a participação na entrevista. Após a assinatura do Termo de Consentimento Livre e Esclarecido coletaram-se as informações, por meio de roteiro de entrevista semiestruturada, incluindo a idade, escolaridade, estado civil, procedência, número de filhos e qual a posição do filho internado em relação aos outros e a pergunta norteadora: o que significa para a senhora a hospitalização do seu filho?

As participantes da pesquisa constituíram-se de 14 mães acompanhantes, após a saturação de informação presentes nas falas. Para manter o anonimato das participantes, utilizaram-se nomes bíblicos como pseudônimos.

O material empírico produzido a partir das entrevistas, foi transcrito na íntegra e organizado em arquivos individuais. $\mathrm{Na}$ análise das informações, foram seguidas as etapas recomendadas pela técnica de análise temática de conteúdo ${ }^{(12)}$ : pré-análise (leitura flutuante e exaustiva do material empírico, buscando mapear os significados atribuídos pelas participantes à questão norteadora da entrevista); análise dos sentidos expressos e latentes (identificação dos núcleos de sentidos, com agregação dos conteúdos afins, ou seja, trecho, ou frases consideradas representativas para a categorização teórica ou empírica); análise final das informações, com elaboração dos temas centrais, por meio da síntese das categorias empíricas, e posterior interpretação das categorias temáticas elencadas. Estas foram discutidas de acordo com as reflexões das pesquisadoras, pautadas na literatura pertinente ao assunto.

\section{RESULTADOS}

A média de idade das mães foi de 32,6 anos, sendo a maioria com idade superior a 28 anos; os extremos de idade foram 19 e 45 anos. Em relação à escolaridade, nenhuma das mães era analfabeta e a maioria havia cursado até o Ensino Fundamental.

A maioria das mães (13) era de procedência do interior do Estado do Ceará; alguns desses municípios são distantes da capital Fortaleza, o que dificultou o acesso dos familiares para o hospital.
Quanto ao número de filhos, cinco mães possuíam apenas um filho, três mães dois filhos, três mães três filhos e duas mães quatro filhos; a maioria das crianças hospitalizadas, era o filho mais novo.

A partir da análise das entrevistas, foi possível descrever aspectos que envolviam a vivência das mães ao acompanharem seus filhos doentes e delimitar duas categorias temáticas: Sentimentos gerados na mãe pelo adoecimento do filho e Estratégias encontradas para enfrentar o sofrimento, a seguir apresentadas.

\section{Sentimentos gerados na mãe pelo adoecimento do filho}

Ao analisar as expressões, para as mães, a internação do filho significou momento de sofrimento:

É assim, a gente sofre as mesmas coisas, a gente sofre
mais! (Raquel)

Estar no hospital acompanhando a internação do filho acarreta sentimentos de tristeza e desespero para a mãe, pois se trata de ambiente diferente, com pessoas desconhecidas para ela, longe de casa e dos familiares, como explicitado nos depoimentos:

Tem dia que eu choro, tem dia que eu estou mais alegre. (Raquel)

Eu sinto uma tristeza de estar com meu filho hospitalizado [...] às vezes eu choro. (Maria)

A mãe sente a doença da criança como algo muito difícil e doloroso e, muitas vezes, esta não encontra palavras para expressar o vivenciado. Sentimentos de dor, tristeza e desânimo foram expressos pelas mães, considerado momento difícil em suas vidas, o qual também acarreta preocupações.

É muito ruim, porque mãe nenhuma quer ter seu filho internado! (Rebeca)

[...] não é bom não, é muito ruim a pessoa ter um filho no hospital, não tem quem queira ter seu filho no hospital. (Ana)

A mãe, na maioria das vezes, é a primeira a perceber que o filho não está bem e que busca por atendimento hospitalar na tentativa de solucionar o problema do filho. Com a notícia da internação, rapidamente faz associação com a gravidade da doença, sendo essa uma 
das principais razões para angústia:

Você sente assim uma angústia [...] primeiro porque você sabe que tem algum problema [...]. (Marta)

Por meio das falas apresentadas, compreendeu-se a problemática na vida das mães acompanhantes, sendo notável a necessidade de estas receberem apoio e cuidado dos profissionais de saúde, por meio de atitude de zelo e cuidado, gerando assistência que englobe o binômio mãe e filho.

\section{Estratégias encontradas para enfrentar o sofrimento}

A despeito do sofrimento gerado com o adoecimento e a hospitalização da criança, as mães encontraram medidas para amenizar a dor. A fé em um ser supremo foi uma das estratégias utilizadas pelas mães para superar esse momento, auxiliando-as a permanecerem no ambiente hospitalar, alcançando forças para lutarem e conseguirem cuidar dos filhos. A visita de religiosos, a participação em grupos de oração, a fé em um ser supremo e o auxílio da comunidade religiosa, são exemplos de apoio religioso a essas mães, como apresentado:

Quero que Deus me dê paciência até o dia que ele sair daqui, que Deus me dê força e coragem. (Raquel)

Nem visita nós temos, sou só eu e ele, só [visita] de Deus mesmo e as meninas, as irmãs que vem orar com a gente. (Sara)

Outra fonte de apoio veio por parte dos profissionais de saúde da unidade. As participantes da pesquisa ressaltaram a importância da atenção desses, auxiliando-as a lidar com o sofrimento vivenciado.

Uma das participantes relatou que, apesar da dificuldade enfrentada durante a internação do filho, sentiu-se muito bem devido a atenção dos profissionais de saúde, esclarecendo dúvidas e anseios, assistindo-os e estando prontos para auxiliá-los, tornando a hospitalização menos angustiante, como relatado:

Não foi uma experiência muito boa, mas graças a Deus, aqui estou sendo muito bem cuidada, ela também [filha]. Estamos sendo muito bem atendidas e eles [profissionais] explicam bem para gente como é que está a criança, o problema dela. Aqui a gente é muito bem tratada, muito bem cuidada pelas mãezinhas, pelos médicos [...] a gente é muito bem cuidada, e as crianças também. (Débora)

Constatou-se, também, por meio dos relatos, que a presença de amigos e o relacionamento com as outras acompanhantes foram benéficos para as mães, uma vez que muitas não receberam o apoio de familiares, devido à distância do hospital aos seus lares, ou mesmo por não terem familiar em que elas pudessem contar durante a vivência hospitalar:

Tenho só uma amiga minha em Fortaleza que sempre ela vem me visitar. (Raquel)

As outras mães conversam, ajudam [...]. (Maria)

Apesar de a maioria das participantes não terem a possibilidade de receber visita de familiares, estes também foram fontes de apoio, pois proporcionaram suporte, estando ao lado dos outros filhos, cuidando da casa e suprindo a família financeira e emocionalmente, como relatado:

A madrinha deles [dos filhos], minha cunhada e madrinha deles é quem ficou cuidando [dos outros filhos]. (Eva)

A partir dessas fontes de apoio, as mães encontraram suporte para cuidarem dos filhos hospitalizados e enfrentarem as dificuldades relacionadas à internação, ao afastamento do lar e outras preocupações.

\section{DISCUSSÃO}

É doloroso e angustiante para as mães terem um filho hospitalizado, por passarem a vivenciar o processo de hospitalização juntamente com eles. Apesar disso, as genitoras são capazes de enfrentar as adversidades para estarem ao lado deles, cuidando e fornecendo apoio para a sua recuperação.

Nesse ambiente estranho, em que o filho é submetido a muitos procedimentos dolorosos, a mãe é envolvida por diversas preocupações que geram sentimentos ambivalentes nessa acompanhante, bem como situações de inconstâncias emocionais, pois o processo de internação pode promover sentimentos confusos e dicotômicos, tanto na criança quanto na família, como alegria e tristeza, cura e morte, entre outros ${ }^{(14)}$.

A situação de adoecimento do filho leva a mãe e os familiares a se defrontarem com um mundo novo, 
fazendo com que percam o sentido de invulnerabilidade e passem a ser invadidos pelo temor, pela dúvida e pelo desespero diante dessa nova situação, o que é agravado pela desinformação e pela ausência de apoio psicossocial $^{(15)}$.

O sofrimento psíquico e a ansiedade da mãe são expressos por meio do choro e das sensações de angústia que caracterizam a somatização dos sentimentos vivenciados por ela, devido à dificuldade que enfrenta ao sair de um ambiente familiar, no qual era adaptada, para estar em um ambiente estranho, tanto em relação à estrutura física quanto às relações estabelecidas, funcionando como um desabafo ${ }^{(16)}$.

Em meio ao sofrimento, as mães sentem a necessidade de receberem suporte emocional. Os profissionais de saúde precisam compreender sua carência, de forma que forneçam cuidado que abranja criança e família no contexto biopsicossocial em que se encontram.

Vivenciar o sofrimento de ter um filho internado pode proporcionar o desencadeamento de transtornos emocionais para as mães, além de tornar o acompanhamento do filho momento estressante e penoso, principalmente quando as mães não recebem apoio e não conseguem enfrentar esse sofrimento ${ }^{(10)}$. De fato, as mães possuem necessidades e desejos a serem supridos, como relacionar-se com outras pessoas, ter momentos de lazer, estar com a família, ter uma vida conjugal, descansar, trabalhar, entre tantos outros.

Nesse sentido, são diferentes os conflitos advindos dos diferentes papéis assumidos pela mulher na sociedade, como mãe, esposa, dona de casa, profissional, o que influencia o seu desgaste emocional. As mães acompanhantes se encontram em difícil situação, com responsabilidades domiciliares, ao mesmo tempo em que querem cumprir os seus deveres de cuidadora ao lado do filho hospitalizado ${ }^{(17)}$.

Em meio a tantas dúvidas e conflitos emocionais, as mães encontraram suporte, que as auxiliaram e confortaram. A religiosidade, por exemplo, é considerada benéfica, por reduzir seu sofrimento mental ${ }^{(10)}$. Ademais, o apoio espiritual e religioso, segundo as suas práticas e crenças, é um direito do acompanhante e da criança hospitalizada de acordo com a resolução n. 41 do Conselho Nacional dos Direitos da Criança e Adolescente ${ }^{(18)}$.

Portanto, cabe às instituições hospitalares fornecerem subsídios para a concretização desse direito, como, por exemplo, disponibilizando locais para reuniões entre religiosos, permitindo o livre acesso dos mesmos às unidades de internação e respeitando as escolhas e costumes de cada família, deixando-as livres para decidir sobre que tipo de suporte desejam receber.
A humanização no ambiente hospitalar envolve o respeito às particularidades e necessidades de cada família/criança, levando-se em consideração os diversos aspectos que permeiam a vida dessas pessoas, como questões culturais, emocionais, sociais, econômicas e biológicas. Nessa perspectiva, os profissionais de saúde têm importante atribuição diante dessas genitoras, gerando assistência mais humanizada, ouvindo-as, esclarecendo dúvidas, estando ao seu lado, compreendendo anseios e angústias, e mantendo relação de respeito e ética.

Outra fonte de apoio é identificada na convivência com outras acompanhantes. A comunicação entre elas torna-se um mecanismo de enfrentamento do sofrimento. Este aspecto também foi observado em outro estudo, no qual algumas mães afirmaram compartilhar anseios e angústias com outras acompanhantes, como recurso para suportarem a situação vivenciada e os sentimentos de medo e solidão ${ }^{(10)}$.

A família é, também, fonte indispensável de apoio para a mãe, fornecendo suporte para que esta consiga permanecer ao lado do filho hospitalizado, por meio de conforto, ajuda financeira, gerenciamento e organização do domicílio, auxilio na manutenção da rotina dos outros filhos, e, algumas vezes, até do revezamento no hospital ${ }^{(19)}$.

Em síntese, as relações sociais são essenciais na vida dessas mães que se veêm, muitas vezes, diante do desconhecido, sozinhas, distantes de casa e da família, carentes de cuidado, o que denota a necessidade do olhar do enfermeiro, incluindo-as no plano assistencial.

\section{CONSIDERAÇÕES FINAIS}

Apesar de sofrerem, as mães abdicam, muitas vezes, de desejos, abandonando a rotina para vivenciar com o filho o processo de hospitalização e a luta em busca da recuperação do seu estado de saúde. Contudo, em meio a essa situação, encontram algumas estratégias capazes de amenizar esse sofrimento, auxiliando-as diante da internação.

Nesse contexto, o ambiente hospitalar também deve dispor de condições para que as mães tenham melhor enfrentamento do processo de hospitalização de seus filhos, concedendo espaços para que possam interagir umas com as outras, ou simplesmente estarem sozinhas, sejam possibilitadas de receberem visitas, vivenciem situações de lazer e usufruam de suas crenças religiosas.

A partir da compreensão dos fatores expostos nesse estudo torna-se possível, portanto, para a equi- 
pe multiprofissional e gestores hospitalares, um olhar mais atento às mães. Faz-se necessário vê-las não mais como meras auxiliares na realização dos cuidados à criança, empecilho para o seu processo de trabalho, ou outra questão para que estes tenham que preocupar-se, todavia como pessoas que juntamente com a criança carecem de cuidado e atenção.

Assim sendo, destaca-se o papel essencial dos profissionais de saúde junto ao binômio mãe e filho como provedores de um cuidado integral, de qualidade e mais humano, acolhendo-os da melhor forma possível, por meio de uma relação ética e de respeito e proporcionando a formação de vínculos terapêuticos.

\section{REFERÊNCIAS}

1. Gomes LVG, Queiros MVO, Bezerra LLAL, Souza NPG. A hospitalização no olhar de crianças e adolescentes: sentimentos e experiências vivenciadas. Cogitare enferm. 2012;17(4):703-9.

2. Brasil. Lei n. 8069, de 13 de julho de 1990. Dispõe sobre o Estatuto da Criança e do Adolescente e dá outras providências. Diário Oficial da República Federativa do Brasil, Brasília, 13 jul. 1990.

3. Bowbly J. Formação e rompimento dos laços afetivos. $3^{a}$ ed. São Paulo: Martins Fontes; 2001.

4. Strasburg AC, Pintanel AC, Gomes GC, Mota MS. Cuidado de enfermagem a crianças hospitalizadas: percepção de mães acompanhantes. Rev. enferm. UERJ. 2011;19(2):262-7.

5. Sabates AL. Reações da criança ou do adolescente e de sua família relacionadas à doença e à hospitalização. In: Almeida FA, Sabates AL, organizadores. Enfermagem pediátrica: a criança, o adolescente e sua família no hospital. Barueri: Manole; 2008. p. 49-56.

6. Hayakawa LY, Marcon SS, Higarashi IH. Alterações familiares decorrentes da internação de um filho em uma unidade de terapia intensiva pediátrica. Rev. Gaúcha Enferm. 2009;30(2):175-82.

7. Morais GSN, Costa SFG. Experiência existencial de mães de crianças hospitalizadas em unidade de terapia intensiva pediátrica. Rev Esc Enferm USP 2009;43(3):639-46.

8. Gomes GC, Erdmann AL, Busanello J. Refletindo sobre a inserção da família no cuidado à criança hospitalizada. Rev. enferm. UERJ. 2010;18(1):143-7.
9. Molina RCM, Marcon SS. Sofrimento psíquico interferindo no desejo materno de cuidar do filho internado na unidade de terapia intensiva pediátrica. Online Braz J Nurs [Internet] 2009;8(3) [acesso em 22 jan 2013] Disponível: http://www.objnursing.uff.br/ index.php/nursing.

10. Costa JB, Mombelli MA, Marcon SS. Avaliação do sofrimento psíquico da mãe acompanhante em alojamento conjunto pediátrico. Estud. psicol. 2009;26(3):317-25.

11. Schultz LF, Sabates AL. A família vivenciando a doença e a hospitalização da criança: estudo qualitativo. Online Braz J Nurs. [Internet] 2010;9(2) [acesso em $21 \mathrm{dez}$ 2011] Disponível: http://www.objnursing.uff.br/index. php/nursing/article/view/j.16764285. 2010.3054/679.

12. Minayo MCS. Pesquisa social: teoria, método e criatividade. Rio de Janeiro: Vozes; 2010.

13. Ministério da Saúde (BR). Conselho Nacional de Saúde. Diretrizes e normas regulamentadoras de pesquisa envolvendo seres humanos. Resolução n. 196, de 10 de outubro de 1996. Brasília; 1996.

14. Azevedo DM, Santos JJS, Justino MAR, Miranda FAN, Simpson CA. O brincar enquanto instrumento terapêutico: opinião dos acompanhantes. Rev. Eletr. Enf. [Internet] 2008;10(1):137-44 [acesso em 07 nov 2011]. Disponível: http://www.fen.ufg.br/fen_revista/ v10/n1/pdf/v10n1a12.pdf.

15. Monteiro CFS, Veloso LUP, Sousa PCB, Morais SCRV. A vivência familiar diante do adoecimento e tratamento de crianças e adolescentes com leucemia linfóide aguda. Cogitare enferm. 2008;13(4):484-9.

16. Leite MF, Gomes IP, Leite MF, Oliveira BRG, Rosin J, Collet N. Condição crônica na infância durante a hospitalização: sofrimento do cuidador familiar. Cienc. cuid. saude. 2012;11(1):51-7.

17. Silva MAS, Collet N, Silva KL, Moura FM. Cotidiano da família no enfrentamento da condição crônica na infância. Acta Paul. Enferm. 2010;23(3):359-65.

18. Ministério da Saúde (BR). Conselho Nacional de Saúde. Diretrizes e normas regulamentadoras de pesquisa envolvendo seres humanos. Resolução n. 196, de 10 de outubro de 1996. Brasília; 1996.

19. Silveira AO, Angelo M, Martins SR. Doença e hospitalização da criança: identificando as habilidades da família. Rev. enferm. UERJ. 2008;16(2):212-7. 